\title{
Development of a graphical resilience framework to understand a coupled human-natural system in a remote arid highland of Baja California Sur
}

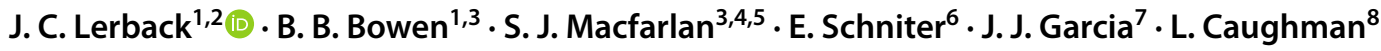

Received: 23 April 2021 / Accepted: 23 December 2021 / Published online: 4 March 2022

(c) The Author(s), under exclusive licence to Springer Japan KK, part of Springer Nature 2022

\begin{abstract}
Hydrological systems are important to society as water resources and effective management requires an understanding of how water and humans influence each other. To describe human-water connections it is necessary to bridge social and natural sciences. To this end, we construct an interdisciplinary graphical framework for evaluating potential human-water system resilience, which is a tool to show the spatial and temporal response to system change of both human and natural systems. This helps to identify the ways that human responses to change relate to changing water resources and identifies important thresholds and potential disconnects that would create vulnerability. We further use this tool to describe a dynamic, coupled human-water system present in the arid Sierra de la Giganta region of Baja California Sur, Mexico. In this remote mountain range, there is a community (self-identifying as Choyeros) who rely on spring water for ranching and subsistence. Using mixed methods of hydrogeochemistry and anthropology, we describe spatial connectivity and temporal changes of both hydrologic and social systems. We use these observations to examine the Choyero response to system changes and explore the topology of the various approaches that the community employs to adapt to changing water availability. The framework guides dialogue to constrain the types of policies, strategies, and responses that help to promote the sustainability of water resources. This framework can be used to compare systems across spatio-temporal scales to produce more generalizable and communicable insights of coupled human-natural systems.
\end{abstract}

Keywords Sustainability $\cdot$ Resilience $\cdot$ Water management $\cdot$ Cultural anthropology $\cdot$ Hydrology $\cdot$ Rural societies

Handled by Kanako Morita, Forestry and Forest Products Research Institute, Tsukuba, Japan.

\section{J. C. Lerback}

jlerback@ucla.edu

1 Department of Geology and Geophysics, University of Utah, Salt Lake City, USA

2 Department of Earth, Planetary, and Space Sciences, University of California, Los Angeles, Los Angeles, USA

3 Global Change and Sustainability Center, University of Utah, Salt Lake City, USA

4 Department of Anthropology, University of Utah, Salt Lake City, USA

5 Center for Latin American Studies, University of Utah, Salt Lake City, USA

6 Center for the Study of Human Nature, California State University Fullerton, Fullerton, USA

7 Salt Lake Community College, Salt Lake City, USA

8 Earth Systems Science for the Anthropocene, Arizona State University, Tempe, USA

\section{Introduction}

Water resources are integral to societal resilience. To achieve effective long-term management, we must understand the complex relationships between the human and hydrological systems. The International Association of Hydrological Sciences posed the question, "How do changes in hydrological systems interact with, and feedback to, natural and social systems driven by hydrological processes?" (Montanari et al. 2013). Answering this fundamental question requires the explicit study of coupled human-natural (also described in the literature as socio-ecological, sociohydrological, or hydrosocial) systems. In these systems, the human and water components are connected and change on different geographical and temporal scales. The integration of the social and hydrologic systems requires accounting for wider potential connected processes than either system alone and should help to facilitate local self-determination of desired governance and goal-setting (Walker et al. 2009a, b; 
Resilience Alliance 2010; Sivapalan et al. 2012; Rockström et al. 2014; Boelens et al. 2016; Lade et al. 2020). Accurate and holistic understanding of the organization of humans in a water-scarce landscape can help to prevent and resolve conflicts between humans and the environment, and amongst humans themselves (Sterling et al. 2020).

The disciplines that have historically addressed these questions are from the physical (hydrology, geography, climatology) and social sciences (anthropology, economics, sociology) (Xu et al. 2018). Disciplines can be defined by having central problems with common explanations, goals, and theories (Darden and Maull 1977). However, in defining inter-disciplines, it is particularly important to develop a common language to form self-referential communities (another key aspect of a "discipline") (Weingart 2010). Interdisciplinary studies can combine the complementary methods of multiple disciplines and common themes of physical and social sciences as they apply to water resources research, but there is a need to more clearly strengthen links between these historically disparate disciplines. These connections will help define the boundaries of a coupled sociohydrological system, which has thus far been ambiguous and sometimes subjective (Mao et al. 2017).

Two primary links between humans and water, resource knowledge and human behavior, are key governing factors in determining socio-hydrological relationships. Distributed (communal) knowledge of the properties of water and the associated water cycle determines what the water is used for. Physical scientists or hydrologists might describe this process as water quality and resource sustainability. That knowledge is then translated into human behavior, or water use. The knowledge-to-behavior translation is mitigated by cultural values, social structures, and regulatory or economic systems. These primary connections also help define the bounds of the water resource of interest-e.g. knowledge of groundwater resources depends on the climate and biophysical characteristics, but only to the extent that those affect water resource use.

More recently, "inter-disciplines" that aspire to bridge these distinct disciplines have emerged called coupled natural-human systems, socio-ecology, political ecology, resilience, sustainability, and socio-hydrology (Xu et al. 2018; Madani and Shafiee-Jood 2020). These linking disciplines combine the complementary methods and common themes of physical and social sciences as they apply to water resources research; however, there is a need to strengthen links more clearly between disciplines.

In this paper, we propose a framework of resilience to more deeply understand interdisciplinary relationships contributing to water resources, sustainability, and resilience research. We present a case study of a socio-hydrologic system in which a relatively isolated community of ranchers in Baja California Sur, Mexico almost exclusively uses local water sources. The case study combines disciplinary methods and results from hydrology and anthropology. We evaluate the spatial and temporal resilience of both the hydrologic and social systems of the case study within the proposed graphical resilience framework. This synthesis and application demonstrates how traditional disciplines can communicate across disciplinary boundaries, converging on shared themes (water). Finally, we discuss the applied utility and limitations of this tool.

\section{Graphical resilience framework}

Sustainability often describes the continuation of static states as goals whereas resilience encompasses the timedependent nature of complex systems as they plan for and respond to stresses or change (Scheffer et al. 2001; Barr and Devine-Wright 2012; Moore et al. 2017). Thus, we primarily present this work as a resilience study rather than a sustainability study because we do not assume a steady state in this dynamic system but do assume a threshold that allows the community to sustain their subsistence lifestyle and not be forced to leave this ecosystem and their homes (Cote and Nightingale 2012). We recognize that there are multiple aspects of resilience including mitigation, adaptation, response and recovery, and that communities need ways to understand the vulnerabilities and strengths of the systems upon which they depend (Doorn et al. 2019). In this study, we develop a tool for resilience planning that integrates information from human and natural systems into simplified graphical representations, depicting the current state of the system, as well as future scenarios that may require mitigation or adaptation. These types of tools have been shown to accelerate learning between researchers and communities while advancing resilience policies and outcomes (Caughman et al. 2020; Iwaniec et al. 2020). Some studies consider resilient coupled human-natural, socio-ecological, and/or socio-hydrological systems as those that "continually change and adapt yet remain within critical thresholds" (Folke et al. 2010). We describe coupled human-natural systems within this framework but do not attempt to assign specific thresholds of "acceptable outcomes" to the system, as we intentionally leave that to be decided by stakeholders and water users in the region of study. Thus, while we speculate on resilience and vulnerabilities, we do not specifically label any such system.

In our proposed framework, we define resilience as the ability of a system to respond to change or stress (Cote and Nightingale 2012). This simplified definition builds from prior definitions described from a socio-ecological perspective encompassing three components of resilience (akin here to "perseverance" or "absorptive capacity"), adaptability, and transformability (Walker et al. 
2004; Folke et al, 2010). This framework draws from the resilience heuristic proposed by Mao et al. (2017) who uses systems theory to describe resilience as the ability to both absorb and adapt to system perturbations. System perturbations and recovery happen over "space" and "time", which we propose can be used as the core conceptual elements to bridge disciplinary fields examining water resources, which reflect the two core variables used in other socio-ecological frameworks (Díaz et al. 2015; Biggs et al. 2018). This framework, in contrast, directly compares multi-disciplinary data within the "response to perturbations" concept of resilience. Physical scientists study the temporal dynamics and spatial connectivity of water systems, and social scientists study the temporal dynamics and spatial connectivity of social systems. These core concepts in each discipline (specifically earth sciences and anthropology in this research) are explored and woven together to provide a different way of evaluating this coupled human-natural system and expand and bridge the disciplines.

This framework also is designed to understand a single system or region of interest. The focus on a single coupled human-natural system allows for stakeholders, scientists, and other parties to engage by applying their own goals, place-based knowledge, and system boundaries. Power differentials between parties and a diversity of values must be considered to equitably understand coupled human-natural systems (Pascual et al. 2017; Thompson et al. 2020). In the spirit of building authentic and trusting relationships with water using communities such as the Choyeros, we designed this graphical framework in the hopes that its simplicity and lack of prescribed "goals" will be accessible, facilitate thorough conversation, and empower stakeholders to have more control and creativity in the narrative the framework can create.

In this resilience framework (Fig. 1), the $x$-axis represents the spatial scale of response to change ("space"), and the $y$-axis represents the temporal scale of response to change ("time"). This bi-plot graphic of spatial and temporal scales have been used by geoscientists and other physical scientists to visualize the scales of earth processes beyond an individuals' experience, such as to synthesize societally relevant components of oceanographic processes (Kavanaugh et al. 2016; Ruhl et al. 2011; Lampitt et al. 2010), or to map hydrological variables impacting urban systems (Cristiano et al. 2017). Here we broaden the framework to explicitly include societally relevant/social science variables by drawing components of "Water" and "Human" systems (artificially divided) as distinct areas within this graphical space. The $y$-dimensions of these areas are determined by the scale of the adaptive response of each system. The $x$-dimensions of the areas are related to the spatial scale over which the resource in question flows: the absorptive capacities of the system. The scope of the water system of study relies heavily on the scope of the resource as defined by human use.

Figure 1a describes zones within the resilience framework for human systems. We consider this to represent aspects of human behavior as responses to human-water system changes. Immediate responses to system perturbations on very short timescales can be considered emergency responses, while long-term changes represent shifts in cultural norms, institutions, and practices. Human responses to change on small spatial scales can be considered individual behavior changes or local norm development. All of these types of responses can be understood through a lens of community-engaged planning, which would ideally allow for scaled responses over a wide range of time and space.

Figure $1 \mathrm{~b}$ similarly describes zones within the resilience framework for hydrologic systems. Rapid hydrologic responses to system perturbations can be described as seasonal fluctuations in resource quality and availability, whereas long-term changes in the water system may be due to geologic processes, such as landscape evolution, tectonic uplift, or fluctuations between glacial and interglacial cycles. Spatially small-scale changes to the water system are influenced by local resource availability and quality, while spatially large-scale changes are regional to global environmental changes that impact water availability such as the structural configuration of aquifers and landscape changes that cause changes in spatial patterns in water table geometry and aquifer characteristics. The scope of the water cycle considered in Fig. 1b depends on the resource knowledge and use by the stakeholders in any particular case study.

As a starting point for this exploration, we propose that when the adaptive and absorptive capacities of a coupled human-natural system overlap in space and time, the system can be considered to be more resilient (Fig. 1c). If one part of the system is changed (either human or water), the other can respond on a similar temporal and/or spatial scale(s). For example, if a drought occurred in a water system on the time scale of years to decades, humans would be able to respond by altering their knowledge, institutions, or demographic composition to shift water use on a similar or shorter time scale, thus adapting through time to absorb the impacts of these changes. Or humans could modify their spatial scale and reach out to more distant water resources. Similarly, overlapping spatial scales allow systems to absorb changes; if a river used by a city is depleted one year, surrounding agriculture might be able to share water resources with the city to meet its essential needs.

In contrast, in a vulnerable system, the human and water systems might be less likely to overlap in space and time. An example of a vulnerable system is shown in Fig. 1d (scenario 1), where human systems operate on large scales and are slow to change, while water systems change rapidly and on more local scales. For example, large, centralized 


\section{A) Human responses to system perturbations}

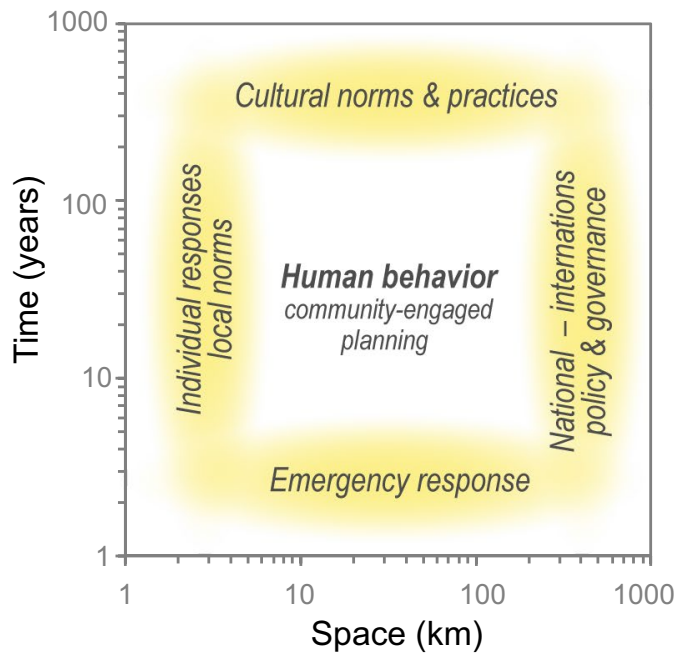

\section{C) Resilient human-water systems}

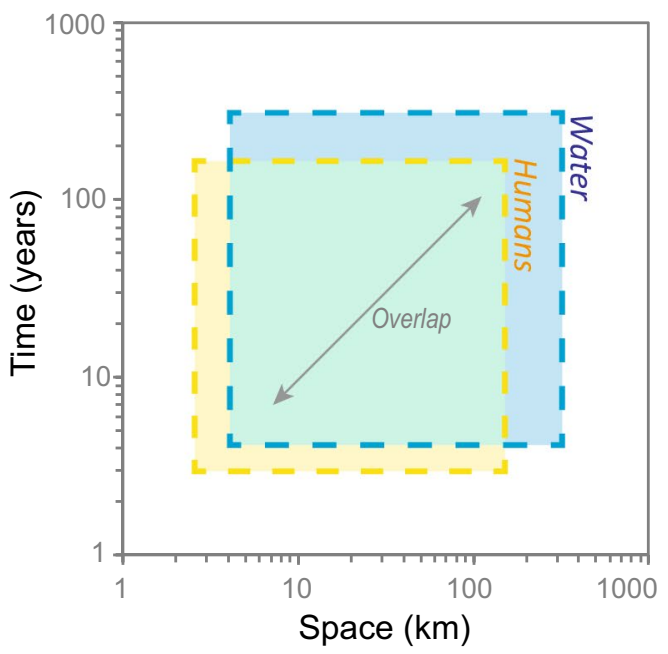

Fig. 1 Resilience framework. Response to social and/or hydrological perturbations can occur across spatial and temporal scales plotted here. These types of response can be thought of as absorptive or adaptive, respectively. a Human behaviors can be seen as responses to system changes or perturbations. Response types within the human response system are described in the yellow-colored zones. b Knowledge of water resources helps describe ways in which the hydrologic system responds to perturbations. Response types within the human response system are described in the blue-colored zones. $\mathbf{c}$ A resilient coupled human-natural system is plotted within the proposed framework. In a resilient system, the scales of the response of both human and water systems overlap significantly. A large adaptive capacity

governments with policies that do not align with ecosystems and resources may encompass a larger space but be less flexible through time. The response time of some social systems would be longer and larger than the response times of water systems, for example, in the lackadaisical global response to climate change. Large, centralized water supply
B) Water responses to system perturbations

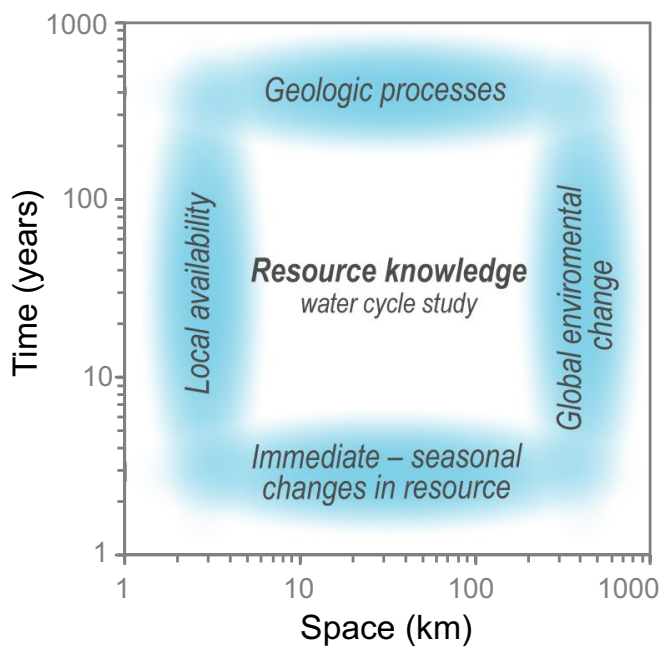

D) Vulnerable human-water systems

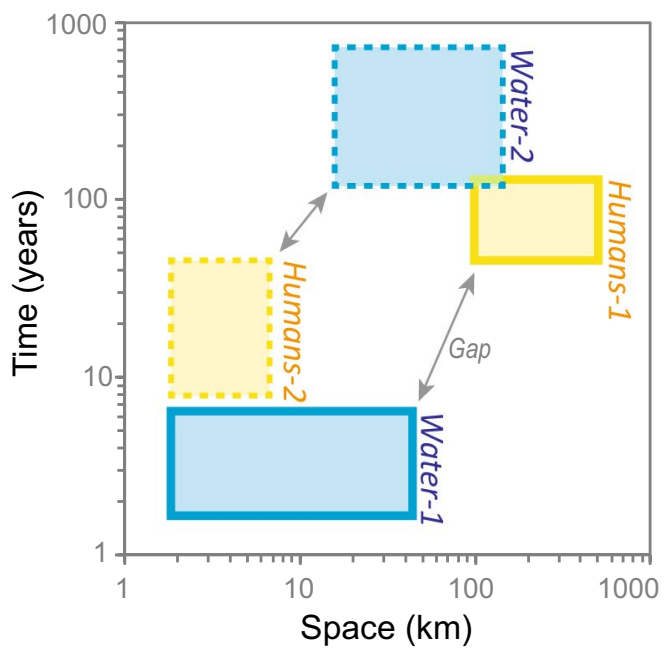

is shown when both systems can respond over a large range of time scales, and a large absorptive capacity occurs when both systems can operate over a large range of spatial scales. d Two examples of vulnerable coupled human-natural systems. The first example (denoted with a "- 1", using solid lines) shows a system where the response scales of humans and water do not overlap. This means that the human and water systems do not respond to change on similar scales and are thus vulnerable to conflict or resource overuse. The second example of a vulnerable coupled human-natural system (" -2 ", dotted lines) where the hydrologic system responds to change on larger temporal and spatial scales than the related human system

infrastructure systems are built to span both space and time to redistribute efficiently in the face of smaller local variability. When there is no overlap between the two connected systems of humans and water over time and space, the system may be more vulnerable to resource loss and/or social conflict. 
Another theoretical example of a vulnerable system is shown in Fig. 1d (scenario 2), where hydrologic systems operate at longer temporal and spatial scales than human systems. This sort of system could be thought of as an arid hydrologic system, where groundwater recharge occurs over thousands of years, and recharge occurs far from the discharge areas, where water is ultimately used by humans (such as a large desert). In this scenario, humans may make up for the disconnect from the time (e.g., ancient recharge) by expanding their spatial footprint, drawing water resources from more distant sources (including with depth). The human system, in this case, would be more local, and perhaps not have political control over policies impacting the hydrologic systems. More scalable control over human systems or more adaptable policies could change the placement and size of the human system.

We build this framework not as a prescriptive and empirical measure of resilience, but rather as a tool meant to translate scientific and sometimes esoteric concepts towards more meaningful policy implications. We hope this tool can help guide conversations between scientists and stakeholders in creative, culturally relevant, and equity-oriented conversations regarding resource management. For instance, this tool can be used to enhance social justice in resilience governance, by giving more opportunities for equitable participation in decision-making activities, and increasing recognitional equity by including community-led social components in the conceptualization of local system dynamics (Meerow et al. 2019).

\section{Application to an interdisciplinary case study}

By studying a social system (a ranching community in Baja California Sur) closely and directly tied to groundwater hydrology (by dependence on springs), we evaluate cultural knowledge and values as they relate to human behavior and resource availability. Our interdisciplinary collaborative structure included shared field experiences where we developed a shared vision of the human-water system (e.g., Massuel et al. 2018). We first describe the social and hydrological systems, then address the following two research questions: How do changes to either or both hydrologic and human systems impact the whole systems' ability to respond to change? And what can these relationships tell us about the resilience and sustainability of this system? To address these questions, we develop and test a transdisciplinary framework, contextualizing "resilience" in these humanand-hydrological systems. This framework helps to facilitate transdisciplinary conversations about complex systems.

This study focuses on a regionally specific spatial and social scale where both the hydrological and social system are isolated and well constrained. As management programs must be appropriately scaled to apply locally appropriate solutions (Ostrom 2009), we recognize that the relationships between the societal and hydrological systems are unique to this small-scale and spring-dependent society. Rural populations have little historical data collection on water use and population, are often economically underserved and have strong traditions giving insight to the development of ecological (and hydrological) knowledge, cultural norms, resource use, and the development of inequality. By focusing on this small-scale example, we scale down complicating factors such as multi-party stakeholders, large populations with unknown contexts, and complex decoupling of water resources and human consumption. This perspective, drawing heavily from cultural anthropology, helps to refine assumptions about cultural knowledge, as well as provides a level of intimacy with the community and data allowing for nuanced interpretations of results.

\section{Site description}

We study the coupled groundwater and social systems of a rural ranching community in Baja California Sur, Mexico. The study site is in the Sierra de la Giganta, a mountain range on the east side of the Baja California Peninsula. This mountain range exists in a hot desert environment that experiences seasonal variation in precipitation due to the North American Monsoon (Salinas Zavala et al. 1990; Barron et al. 2012; Macfarlan et al 2021) (Fig. 2). Aridland springs here have supported human societies (i.e., indigenous populations, Jesuit missionaries, and Euro-Mexican colonists) for at least 5000 years (Henrickson 2013). These springs provide the only source of permanent freshwater for the community. Hence, they are important cultural sites and social hubs.

Currently, the springs support a traditional ranching population of $\sim 4000$ people, self-identified as Choyeros (named after the cholla cactus (Cylindropuntia cholla) common to that part of the desert) or rancheros, but also known as Oasiana-Rancheros or Californios in the academic literature (Crosby 1981; Cariño 2001; Comisión Nacional de Áreas Naturales Protegidas 2014; de Grenade et al. 2016; Macfarlan et al. 2020b; Schniter et al. 2021) (Fig. 3a). Modern Choyeros are descended from several waves of Euro-American colonists who began settling the region in the late-17th and early-eighteenth centuries, following the establishment of the first Jesuit mission in Loreto (Crosby 1994; Vernon 2002; Schacht et al. 2020). These are some of the most underserved communities throughout Baja California Sur, lacking access to a range of amenities, including piped water, sanitation services, permanent electricity, and medical facilities (Comisión Nacional de Áreas Naturales Protegidas 2014; Secretaría de Desarrollo Social 2019). Choyero community members have observed expansion of 

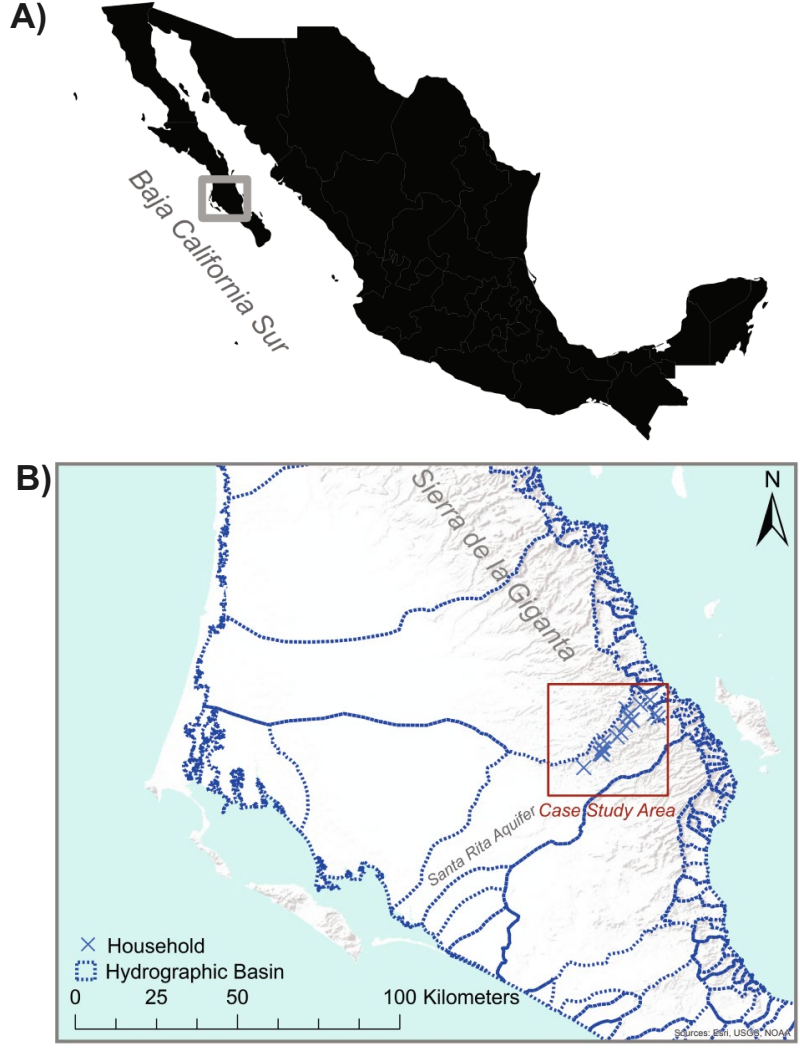

Fig. 2 Study area. a Map of Mexico with a grey square indicating the map extent in the panel below. b Map of the study region, where Choyero communities reside in the Sierra de La Giganta within the State of Baja California Sur in Mexico. Ranch locations (households surveyed for this study) are shown within a red rectangle, which indicates the map extent of Fig. 3a

water use regionally and informally expressed concerns over changes to land-use policy impacting their access to spring ecosystems and grazing areas. They aim for their long-term cultural survival, recognizing that their culture is tethered to the springwater oases.

The subdelegation of Santa Maria de Toris, located in the municipality of La Paz was composed of 113 permanent residents living in 32 active ranches at the time of our study. Active ranches exist on a patchwork of property rights regimes, including private property $(n=17)$, common-pool landholding entities known as ejidos ( $n=3$; Ejido Ley Federal de Agua \#2 and Ejido Tepentu), and twelve which either lack land title or have a land title that is in dispute.

This system represents a contrast to other coupled humannatural systems as there is not yet technologically driven over production of water resources for agriculture which could rapidly lower water table levels, reducing the water in spring oases. Due to the lack of regionally connective water infrastructure, Choyeros are dependent on the arid land springs for their survival and livelihoods (Crosby 1981; McLean et al. 1986; de Grenade et al. 2016). Choyero's
A)

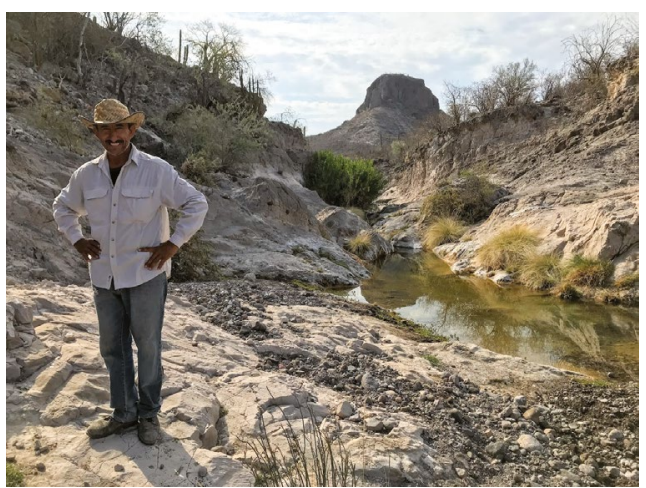

B)

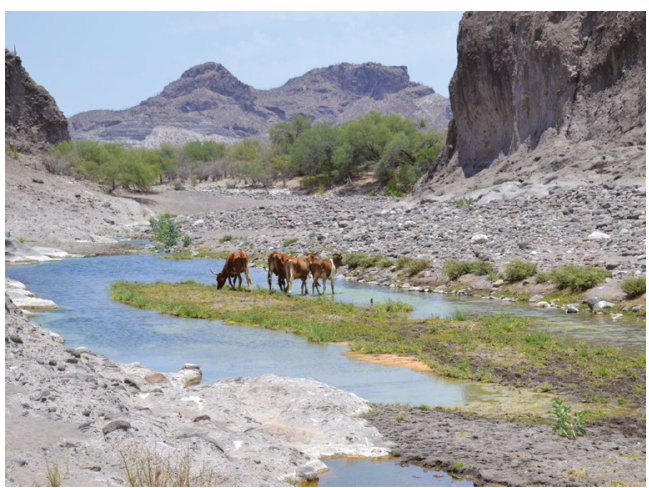

Fig. 3 Choyeros and water resources. a A Choyero who lives in the study area and participated in this study is shown standing next to a flowing spring. Some ranches use gravity and plastic tubing to feed water up to $5 \mathrm{~km}$ from springs to households, which are preferentially built near roads. b Ranchers' economic livelihoods are tethered to cows and the springs

economic livelihoods focus on goat and cattle ranching for domestic consumption and sale on local and regional markets (Fig. 3b). Because Choyero economic livelihoods are tethered to the springs, ranches tend to be located wherever springs exist with homes predominantly located on flatlands above dry riverbeds near springs on valley bottoms. This causes households to be separated from one another by large distances and makes communities highly dispersed with small population sizes (Macfarlan et al. 2020b). Even though the community is dispersed across the rugged terrain, this is a close-knit small-scale society where community networks and informal relationships facilitate adaptation to the limited water resource availability.

We note that this manuscript is part of an on-going research program working consistently with and for Choyeros to best and most respectfully support them (Cartier 2020).

\section{Methods}

This study used a mixed-methods approach to understand the hydrologic and social components of the coupled 
human-natural system. First, we describe the hydrological system by summarizing the results and interpretations described in depth in Lerback et al. (2022). This descriptive study of the hydrogeochemistry includes a survey of springs and wells along a canyon-transect surrounding the sub-delegation of Santa Maria de Toris. Twenty-four springs and two wells were sampled for major ion, trace element, and/or isotopic $\left(\delta^{18} \mathrm{O}, \delta^{2} \mathrm{H}\right.$, tritium, and radiocarbon) analyses in 2017 and 2018.

The focus on a small community where whole-network surveys are possible (as opposed to incomplete sampling) is desirable for water sharing and social network analyses (Wasserman and Faust 2009). Between June 16 and July 1 of 2017, the research team performed household censuses of 31 of 32 ranches spanning the same region as the springs that were evaluated in this study area (Fig. 4a). One household was not available for an interview during the field campaign due to extenuating circumstances. All interviews were conducted in Spanish in the privacy of residents' homes. Institutional review board approval was obtained through the University of Utah (IRB\# 00083096), and community approval to conduct research was obtained through the sub-delegation of the Santa Maria de Toris. These methods both qualitatively and quantitatively measured community resource knowledge, social networks, and behavior.

During the interviews, questions regarding ecosystem experiences and ecosystem knowledge as well as questions eliciting personal social networks were asked (Table 1). We employed structured interviews for ecosystem experience, social network data classes, and semi-structured interviewing with open-ended questions for ecosystem-knowledge data classes (Bernard 2002). When a theme is derived from open-ended interviews, it reflects an interviewee stating a class of related information unprompted by a specific question by the interviewer. The number of ranches describing a theme $(n)$ is reported. Note that the number of ranches reporting a theme reflects the ranches that report information in the open-ended interview but is not necessarily indicative of the total number of ranches in agreement with regard to that theme. A subset of 14 ranches was asked to assess daily household water consumption by providing the size and number of water containers used at their household in a day. This reflects a convenience sample based on proximity to our field camp and driving accessibility during the field campaign. This information was then incorporated with our household census data to estimate daily per capita water consumption rates. Network analyses were performed in STATA IC/15.0 using the nwcommands suite (Hedstrom and Grund 2020).
(A)

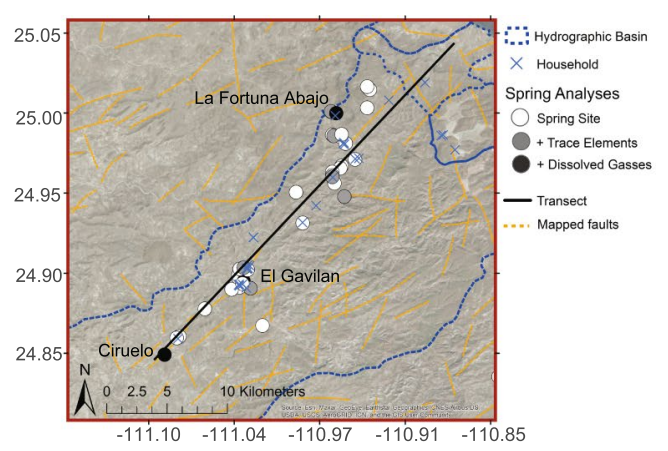

(B)
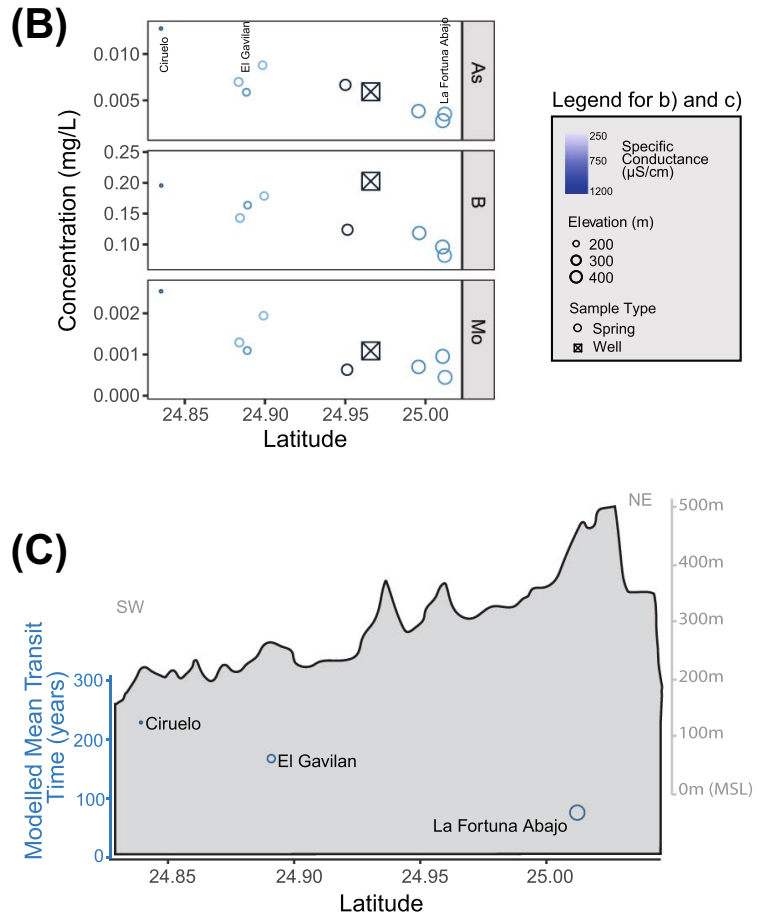

Fig. 4 Hydrologic system characterization. a Sample location and analyses type shown on aerial imagery in relation to the ranches interviewed. Map extent is shown by the red rectangle in Fig. 1b. b Spring trace element anion solute chemistry. Arsenic, boron, and molybdenum concentrations increase down-canyon (decreasing latitude). c Modelled ${ }^{14} \mathrm{C}$ groundwater transit time for three springs along canyon transect. Tritium sampling sites are displayed above the simplified topographic map which follows the transect displayed in Fig. 3a. Figures summarized with permission from Lerback et al. (2022)

\section{Results and interpretation}

We present the results of hydrological and anthropological approaches to interpreting the coupled human-natural system of our study in the remote arid highlands of Baja California Sur.

\section{Hydrologic system}

By estimating aquifer connectivity and groundwater residence times through the study of spring geochemistry, we 
Table 1 Data classes and associated questions used in the study

\begin{tabular}{|c|c|}
\hline Data Classes & Question \\
\hline \multirow[t]{3}{*}{ Ecosystem Experience } & Have you ever experienced a spring going dry during your lifetime? \\
\hline & $\begin{array}{l}\text { Have you ever heard a story from your family (e.g. parents, grandparents, great-grandparents) about } \\
\text { a spring ever running dry? }\end{array}$ \\
\hline & Do you worry about springs running dry now or in the future? \\
\hline \multirow[t]{3}{*}{ Ecosystem Knowledge } & What cause(s) the springs to exist? \\
\hline & What is the relationship between precipitation and the dynamics of spring water? \\
\hline & What is the relationship between precipitation and the dynamics of plant and animal health? \\
\hline \multirow[t]{3}{*}{ Social Networks } & Water Sharing-From whom do you request water? \\
\hline & Male Labor Sharing: When livestock go missing from whom do you ask for assistance? \\
\hline & Female Labor Sharing: When you want to sell artisanal crafts, from whom do you ask for assi \\
\hline
\end{tabular}

These questions were designed to evaluate traditional ecological knowledge, construct cultural models, and understand social networks

constrain the response rates of changes to the hydrologic system. The structurally and compositionally complex geology of the aquifer material and the surrounding terrain makes geochemical analyses of the springs an important approach for understanding the overall groundwater system. These fractured rock, arid, mountain aquifers are not generalizable from the literature, so direct measurements are important to understand local groundwater properties (Cook 2003; Ofterdinger et al. 2019).

In Lerback et al. (2022), stable water isotopes and trace element data of springs and shallow wells are used to understand whether the aquifer that sources the spring is segmented due to numerous faults and discontinuous lithologic facies. These data were interpreted to suggest hydrologic connectivity following the general topographic gradient (Fig. 4b). Similarly, the carbon isotope evolution and residence time models support the hypothesis that the springs are hydrologically connected throughout the transect, despite the complex structure and stratigraphy of the aquifer material. These data suggest that perturbations (e.g., excessive extraction, pollution) to an area of the aquifer may impact the neighboring springs.

Radiocarbon $\left({ }^{14} \mathrm{C}\right)$ and tritium were leveraged by Lerback et al. (2022) to understand residence times of water discharging at springs (or groundwater "ages") (Fig. 4c). The geographical distribution of ages throughout the canyon can help us understand the rate of aquifer recharge. La Fortuna Abajo is the highest elevation spring with a modeled ${ }^{14} \mathrm{C}$ transit time of $75 \pm 6$ years (model originally developed by Fontes and Garnier 1979, and updated by Han and Plummer 2016). The lowest spring sampled for radiocarbon had a modeled age of $230 \pm 23$ years. These ages can either represent (1) an average, consistent recharge or (2) a transient recharge regime where there was event-driven recharge around 200 years ago. Recharge to this aquifer system might also be a combination of these two scenarios.
Insights from this geochemistry help us determine the boundaries within the graphical resilience framework. While this hydrological study is not comprehensive in its ability to predict flooding events or droughts, we understand that the springwater in the area of interest is likely connected within the canyon, and spring availability may respond to recharge rate changes within the lifetime of the Choyeros who use them. More specifics of system perturbations and hydrologic responses as related to the coupled human-natural system are discussed in "Responses to change" section.

\section{Social system}

Physical hydrology affects self-organization and cooperation in societies persistently living in arid areas (Western 1982; Habiba et al. 2012). More pertinently, spring location greatly influences internal community structure, where members with the clear land title have the cheapest access to water and legal authorization to extract it.

Humans have utilized Sierra de la Giganta spring ecosystems for millennia; however, Euro-American ranching populations only began to permanently use those of the study site following the establishment of Jesuit mission Nuestra Señora de Los Dolores del Sur Chillá in 1741 (Crosby 1994; Vernon 2002). Over the last $\sim 280$ years, these ranching populations have developed a cultural toolkit for managing life in this arid ecosystem (Macfarlan et al. 2020a, , 2021; b). Choyero ranchers embody a great body of ethnobiological knowledge: elsewhere we detail the vast inventory of 287 known plants and animals that Choyeros identify by name, know traits and uses of, and which are important to their way of life (Schniter et al. 2020).

Choyero cultural knowledge of hydrologic processes to ecological processes was derived from text analysis of semi-structured and open-ended interviews. These Choyero cultural models are presented in Table 2. Every household agreed that the springs were vital to Choyero subsistence. 
Table 2 Choyero cultural models of hydrologic and biotic processes

Theme of Choyero Knowledge

1. Precipitation and biotic processes: We live in a desert - when it rains, the plants respond by turning green or blooming. $(n=31)$

2. Precipitation and biotic processes: When the desert blooms, livestock benefit by having more food available. $(n=29)$

3. Precipitation and biotic processes: When there is more food and water for livestock, they respond by getting fatter and experience less sickness. $(n=29)$

4. Precipitation and biotic processes: Too much rainwater was not good for livestock, as the resulting floods can cause livestock to become lost or die (e.g. get washed away). $(n=3)$

5. Precipitation and hydrologic processes: A relationship exists between precipitation and spring water. $(n=29)$

6. Precipitation and hydrologic processes: Rainwater does not cause the springs to flow. Instead, rainwater simply causes the existing spring water levels to increase above their normal size. $(n=31)$

7. Precipitation and hydrologic processes: Rainwater gets sucked into the ground and may impact the underground river. However, this is not the primary source water for springs. $(n=5)$

8. Spring hydrodynamics: Spring water is different from rainwater (one comes from holes in the Earth, the other comes from clouds in the sky). $(n=31)$

9. Spring hydrodynamics: An underground system of rivers exists below the arroyo

$(n=30)$

10. Spring hydrodynamics: These rivers can flow horizontally and vertically but emanate from an unknown source or process (but likely derived by God). $(n=30)$

11. Spring hydrodynamics: When these rivers flow vertically to the surface it will leave through tiny openings in the bedrock (called an "ojo de agua")- - this is what causes a spring to exist. $(n=30)$

12. Spring hydrodynamics: Although spring water levels can fluctuate throughout the year, it is always present. $(n=31)$

13. Spring hydrodynamics: During the driest part of the year (April-June), spring water levels recede due to human and animal use, as well as evaporation. $(n=31)$

14. Spring hydrodynamics: During the summer monsoonal rain season (July-October), precipitation causes the spring water levels to increase which is due to two factors; 1. impending rains "call" to the springs to release more water and at a faster rate and 2. rainwater "fills up" the springs. $(n=31)$

15. Spring hydrodynamics: Although a portion of rainwater will sit in springs, the vast majority flows back to the ocean, with percolation of precipitation playing no role in maintaining the underground rivers. $(n=25)$

16. Spring hydrodynamics: Some spring water evaporates into the clouds. $(n=2)$

17. Spring hydrodynamics: Human spring water extraction does not affect the overall composition of the underground rivers. $(n=5)$

Open-ended interviews are performed with 31 households to construct cultural models and understand traditional ecological knowledge

While they understand the economic and cultural importance of these springs, they have not experienced spring water shortages. Of the 31 ranches interviewed, 30 stated that they never experienced a spring running dry and none had ever heard a story from their ancestors about springs going dry, and one out of the 31 had heard a second-hand story of a spring drying. However, 26 households worried that the springs will go dry someday. This has produced a cultural model where springs are seen as nearly infinite in their ability to provide water.

Our interviews suggest that Choyeros value the spring ecosystem for supporting their lives and livelihoods. However, unlike other populations, we find no spiritual or religious conceptions about spring water (e.g., Shaw and Francis 2014; Anderson et al. 2013; Wilson 2018). As such, the relationship between Choyeros and spring water appears to be more utilitarian in nature.

To assess water-sharing networks and uncover the factors that impact the structure of water sharing, we leveraged social network analysis (Bodin et al. 2006; Wasserman and
Faust 2009). Analysis of the water sharing network showed that it is sparsely connected (density $=0.03$ ) with only three percent of all possible inter-ranch water relationships present (32 water sharing connections divided by 930 possible connections) (Table 3). Nine ranches never solicited water from another ranch, twelve solicited water from one other ranch, and ten solicited water from two ranches. The network is displayed as a sociogram in Fig. 5a, and is composed of three discrete water-sharing subcomponents (as well as several isolates who neither receive nor give requests for water). These subcomponents are related to geographic location, although that information has been removed from the shared data to maintain participant privacy.

While the above network analyses suggest that water sharing is modest in scope, additional analyses (see Supplementary Information) suggest that it is a socially important activity that is related to other facets of social life (e.g. labor sharing and residential proximity). Spring water was more likely to be shared between ranches if they had helped one another in labor and if they were physically located closer 
Table 3 Social networks

\begin{tabular}{llllllll}
\hline Variable & Network type & Nodes & Arcs & Density & Transitivity & Mean (SD) & Min/Max \\
\hline Water Sharing & Binary, Directed & 31 & 32 & 0.03 & 0.75 & - & - \\
Labor Sharing & Binary, Directed & 31 & 146 & 0.16 & 0.63 & - & - \\
Ranch Proximity $(\mathrm{Km})$ & Valued, Symmetric & 31 & 930 & - & - & $9.1(6.7)$ & $0 / 28$ \\
\hline
\end{tabular}

Descriptive statistics associated with Choyero water sharing, labor assistance, and ranch proximity networks

to one another. Two-thirds of households maintain a watersharing relationship with at least one other ranch and ranchers adapt their water requests to deal with seasonal or interannual water dynamics. Clusters of water sharing networks increased water demand at associated aquifer withdrawal points. These clusters also are associated with more economic capital and increased withdrawal with infrastructure such as groundwater wells and gas/diesel/solar pumps.

\section{A) Water Sharing Network}
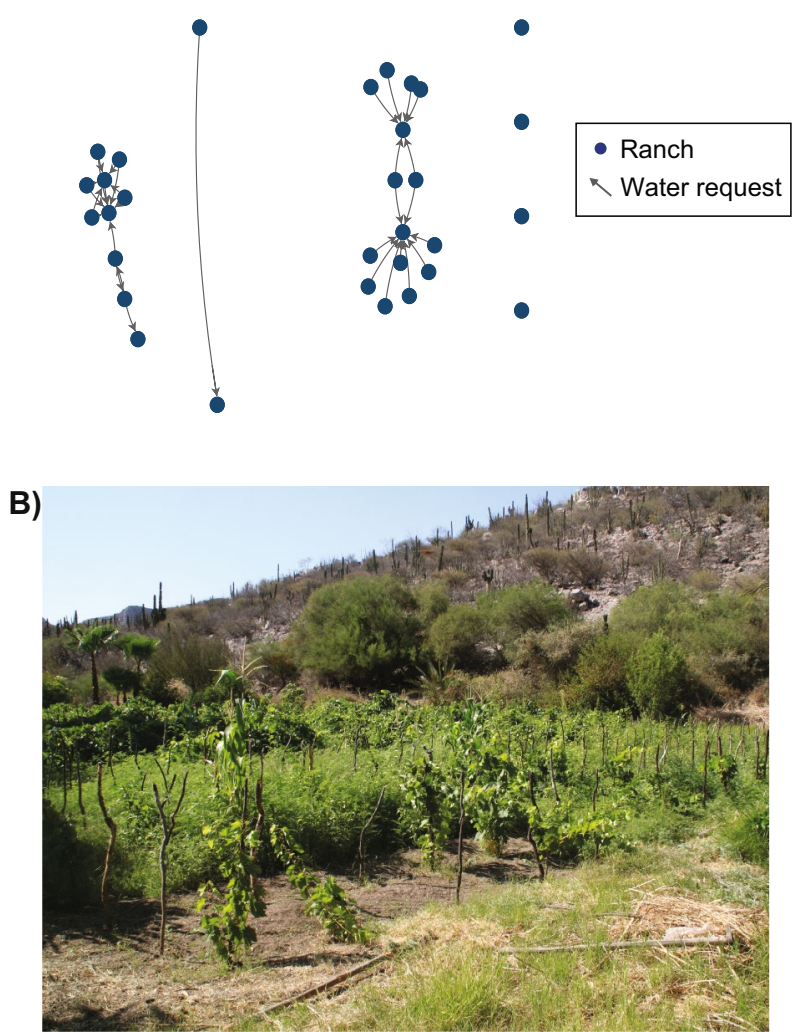

Fig. 5 Choyero subsistence water use. a A sociogram, or visualization of the water sharing network, within the Choyero community participants. Arrowed lines represent water requests from one ranch to another, and line length means nothing. Geographic position of households is obscured to represent participant anonymity, and displayed using a spring embedded algorithm in STATA IC/15.0. The 4 isolated circles represent ranches that neither request water nor receive requests. $\mathbf{b}$ An example of a huerta, a food-producing garden, at a ranch
Water use is not decoupled from the ecological system; human use provides avenues of subsistence as well as provides resources and habitat for many endemic species. Many households maintain food-producing gardens (known as huertas) that maintain the agricultural heritage of their Jesuit forebearers, including crops such as oranges, limes, papaya, coconut, the date palm, and alfalfa. These crops promote food security, supplement the diets of their herds in the absence of well-developed markets, and act as genetic refuges for heritage crops introduced by the Jesuits (Nabhan et al. 2010; de Grenade and Nabhan 2013a, b; de Grenade et al. 2016) (Fig. 5b).

Although residents do not specifically monitor their extraction of spring or well water, they are knowledgeable about the amount of water that is withdrawn generally, as they are aware of the size and number of water containers that they fill regularly to supply household (and dependent households) needs. Based on our analysis of fourteen ranches, households use on average $2900 \mathrm{~L}$ of water per day $($ range $=68-10,645 \mathrm{~L} /$ day; median $=1015 \mathrm{~L} /$ day, $\sim 1$ million L/yr) (Table 4). After factoring for family size, this results in an average per capita daily water usage of 702 $\mathrm{L}$ (range $=34-2593 \mathrm{~L} /$ day; median $=282 \mathrm{~L} /$ day). These numbers include domestic (i.e. households, gardens), agricultural, and ranching uses. Households with a foodproducing garden (i.e. a huerta) use a mean of $1228 \mathrm{~L} /$ day ( $n=5, \mathrm{SD}=955 \mathrm{~L} /$ day), whereas those without one use a mean of $410 \mathrm{~L} /$ day $(n=9, \mathrm{SD}=517 \mathrm{~L} /$ day $)$. A post-hoc Poisson regression analysis run in STATA/IC 15 shows that this difference is significant [Pseudo R2 $=0.41 ; p<0.008$; $n=14$; Huerta: Incident Rate Ratio (Robust Standard Error $)=4.4(2.5)]$.

Ranches are generally established near springs; however, as the population has grown over time, ideal human habitats have become occupied, causing some individuals to locate homes in areas that require water to be extracted with wells, shared by neighbors, or transported from distant sources. Four wells have been constructed in the community center of Santa Maria de Toris beginning in 1980 which are considered to be the property of three households and a rural school (Fig. 6a). These shallow wells were hand-dug and powered with gasoline pumps (Fig. 6b). Households without direct spring access often transport water in barrels on trucks (Fig. 6c) or use several kilometers of plastic piping 
Table 4 Social dynamics

\begin{tabular}{lllllll}
\hline Variable & $n$ & Mean (SD) & Median & Min/Max & Yes & No \\
\hline Ranch Family Size & 31 & $3.5(1.5)$ & 3 & 8 -Jan & - & - \\
Daily Household Water Usage (L) & 14 & $2902(3567)$ & 1015 & $68 / 10645$ & - & - \\
Per Capita Household Water Usage (L) & 14 & $702(781)$ & 283 & $34 / 2593$ & - & - \\
Ranch Has Huerta & 31 & - & - & - & 13 & 18 \\
Indegree Water Sharing & 31 & $1(2.3)$ & 0 & $0 / 9$ & - & - \\
Indegree Labor Sharing & 31 & $4.7(3.1)$ & 4 & $0 / 13$ & - & - \\
\hline
\end{tabular}

Descriptive statistics associated with Choyero social dynamics

(A)

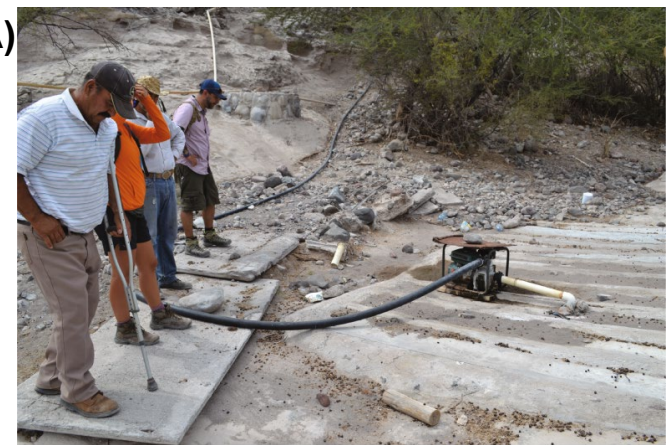

(B)

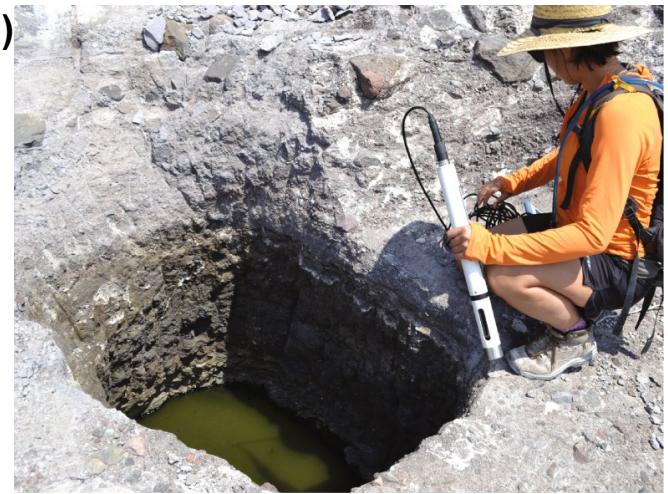

(C)

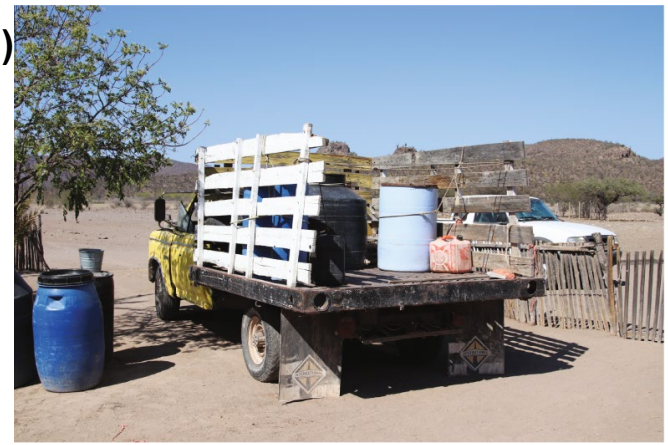

Fig. 6 Choyero water transportation systems. a A shallow well was excavated by hand in the arroyo adjacent to Santa Maria de Toris, the community center. These wells are powered by gasoline pumps to move water about $100 \mathrm{~m}$ for use by the school and community. $\mathbf{b}$ A shallow well recently excavated $\sim 400 \mathrm{~m}$ from a ranch, $200 \mathrm{~m}$ downstream from a spring whose water quality is compromised from the use by ranch animals. $\mathbf{c}$ When a household does not have direct access to a spring or well, they truck barrels of water from a neighboring ranch who has access to a spring. This trip must be made every five days, taking about two hours each time to have a more permanent (but high maintenance) method of water transport.

Our interviews suggest that the Choyero community did not actively or intentionally conserve spring water. This is driven by the fact that they have not experienced springs going dry and which has led to a belief that the springs are nearly infinite in their capability to provide fresh water. However, spring water conservation appears to emerge in this context due to differences of scale (a small population with relatively small extraction rates using a large resource pool, de facto sustainability) - something described in social science literature as epiphenomenal conservation (Bogerhoff-Mulder and Coppolillo 2005). By conducting this research and through our engagement with the community, it is clear that many households are interested in transitioning to an intentional conservation model as their livelihoods and cultural survival are tethered to this resource. We hope to leverage our graphical resilience framework to engage with ranching households throughout the region to convey information about local hydrology as well as an opportunity for us to learn about additional constraints on behavior within this system.

\section{Responses to change}

Resilience can be thought of as the ability of a system to respond to stresses or change, consisting of both absorptive and adaptive capacities (Mao et al. 2017). An important aspect of this work is that we are addressing and assessing aspects of coupled human-natural system change based on formally and informally expressed concerns of the community, rather than measuring and quantifying system disruptions. Here we discuss examples of how the coupled human-natural system of the Sierra de la Giganta responds to changes and stress in both absorptive and adaptive capacities. These changes, and associated responses are described in Table 5.

Non-human and human actions can affect the hydrologic system (e.g., aquifer recharge rates), which in turn affect Choyero's spring water quality and water availability. Changes in groundwater infiltration can be due to either a change in precipitation available (climate) or a change in 
the infiltration capacity of the system. Climate varies on seasonal to millennial time scales and climate variation are influenced by anthropogenic and natural forces. A change to infiltration capacity could also be due to factors such as soil changes related to local land-use changes (e.g., increased grazing due to economic or population pressures leads to harmful soil compaction and desertification) or structural deformation of the rock units through which the water flows.

Institutional and infrastructural changes to this rural area impact demand on groundwater resources. For example, in 1980 , the construction of a rural primary school, dormitory, and shallow ( $3 \mathrm{~m}$ deep) groundwater well in the community center of Toris, not only led to temporary larger population sizes (children from several communities stay at the school for five days per week) and therefore greater water extraction from a single point source, but it also led to at least three additional households to install wells of their own in the same vicinity. Today, one of these households' provisions nine other homes with water. The increased demand on several wells leads to groundwater drawdown, temporarily decreasing the amount of water available to the wells near Toris. Users report that the water level typically recovered within 3-5 days. Thus, as technology and its access have changed over several decades, the groundwater system has so far been able to respond.

This change in technology and increased availability of groundwater also allowed the wells in Santa Maria de Toris to serve a broader Choyero community, providing water to school children from throughout the watershed. Another change in technology in the last decade is the use of market-bought or government-supplied materials (e.g., pipes, tubes, solar and gas-powered pumps) to transport water from springs to houses (whereas before water was moved exclusively with local materials and gravity). The geographical distribution of the community and their water use consequently expanded and became denser near infrastructure services (e.g. wells).

When changes to the hydrological system occur, individuals and families respond by dynamically adapting their networks or their physical location to meet household needs. Adapting one's social network occurs in the context of primary and secondary water-sharing relationships. For example, when seasonal rains cause springs to accumulate debris that makes spring water undrinkable through a preferred water-sharing partner, households rely on consistent secondary partners to provide water for several weeks to months at a time.

Large-scale institutional changes impact how watersharing networks develop. The promulgation of the North American Free Trade Agreement (NAFTA) in 1994 initiated changes in how ranchers interacted with the hydrological system. Although these ranchers and their ancestors have resided in this region since the eighteenth century, many 
lack clear title to their lands. While ranchers state they had little concern for property rights prior to NAFTA, after it, clear title to land became an important consideration. Those with clear title could receive financial and technological assistance through governmental programs (Janvry et al. 1997), including materials for extracting (e.g., solar powered water pumps) and storing groundwater (e.g., concrete water tanks). Households that have obtained these goods now have become focal points for water transfers. As a result, some springs are used more frequently than others.

Water redistribution is a driver of social structures globally (Wutich et al. 2018) and occurs in a number of contexts (e.g., market exchange, reciprocal exchange, gifting). Choyero water-sharing patterns generally align with other agro-pastoralists, as informal water-sharing occurs between socially differentiated (with regard to water access) neighbors to increase community security (Wutich et al. 2018). Privatization of land related to NAFTA, in conjunction with regulatory changes in how water permission is obtained and allocated, have constrained household movement, and thus water sharing must adjust for new differential access to water. Wutich et al. (2018) suggest that this privatization may increase the need for water sharing but limit the community's ability to facilitate exchanges.

\section{Evaluation within framework}

We evaluate the potential resilience of coupled hydrologic and social systems (i.e., their potential to respond to stresses or change) within the context of spatial and temporal responses to water resource perturbations.

The social and hydrological systems of the Sierra de la Giganta are related and changes to one system affect the other, leading to a co-evolved human-water system (Sivapalan et al. 2012). Multiple variables are important for the resilience of this coupled human-natural system: temporal patterns of water cycles (such as rate of groundwater recharge), spatial extent of water systems (aquifer connectivity), human behavior (water usage rates), and social structure (community water sharing). Thus, we use this coupled system to test the utility of the graphical resilience framework developed and described in the preceding section (Trosper 2005).

We evaluate "human" and "water" areas within the context of the Choyero-spring system (Fig. 7). These are the Choyero community of Santa Maria de Toris and the spring water system which they use, respectively. Table 5 reviews the results presented in "Results and interpretation" section to identify perturbations to the human or water system and describe the associated response in terms of spatial and temporal scales.

The spatial component of "water" refers to the connectivity of the spring water system. While there may be

\section{Choyero-Spring Resilience}

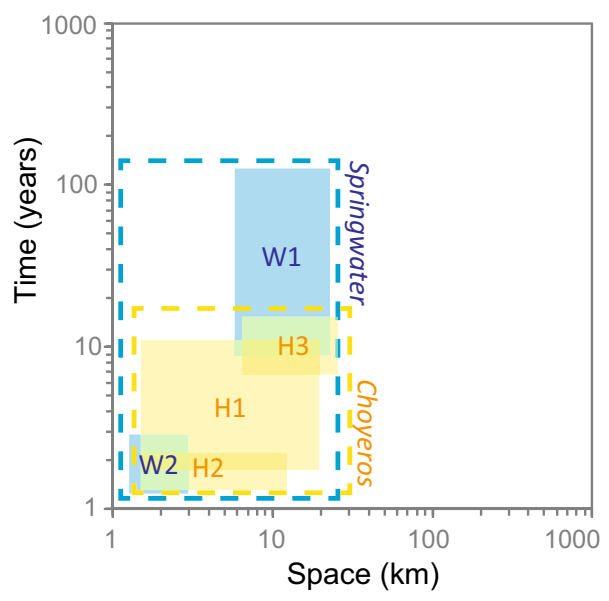

Fig. 7 Evaluation of Choyero coupled human-natural system resilience. This plots the Choyero-spring system's responses to change within the resilience framework shown in Fig. 1 and described in Table 5 and the section titled "Responses to change". Yellow/ lighter boxes (labelled P1-P3) refer to Choyero responses to changes, and blue/darker boxes (labelled W2 and W2) refer to the spring water hydrology system as it responds to change. These are described in Table 5. The Choyero-springwater system is resilient on multi-decadal and seasonal time scales but may be vulnerable to resource stress on yearly or decadal scales

different source waters for groundwater within the canyon, the spatial extent of the canyon is on the order of 1-10's of $\mathrm{km}$. In other systems, further development of infrastructure or trade can expand this spatial extent to 100's or 1000 's of $\mathrm{km}$. Thus, policy and technological factors have an influence over this factor.

The temporal component for the spring water system can be conceptualized by the raising or lowering of the water table as a hydraulic response to changes in recharge or discharge, or by the time it takes water to move through the aquifer. The elevation of the water table raises or lowers depending on rates of input and output, and when the water table intersects the land surface, spring discharge can occur. This change in water table elevation can happen on a rapid time scale from significant increases in groundwater extraction. In basins with groundwater pumping, the drying of springs is often the first noticeable hydrologic change. Discharge rates can be changed by the installation and use of groundwater wells and extraction by municipalities or industry. In this system, the extraction of groundwater by houses was not seen to cause a measurable hydraulic response in the water table elevation. Recharge rates are also affected by climate changes and precipitation regimes. Changes in land cover responding to climate shifts might also influence the speed and magnitude of groundwater infiltration and recharge. We found that 
changes to groundwater recharge rates occur over the order of several decades to centuries, depending on whether the system has steady or transient recharge.

The spatial component of "humans" here refers to how water is shared within the social system. Water was not observed to be shared beyond the canyon, and often was shared between the most proximal ranches (1-10's of km). Water sharing within the social structure is determined by the community's values regarding the water (a utilitarian, available resource, that is associated with other forms of sharing and reflective of power-holding within the community). Other systems might have a more formal economy with money and policies shaping the social networks through which water flows (Lansing 2006).

The temporal component of "humans" is determined by the time for humans to adjust their use of water. Choyero knowledge and experiences of the groundwater system primarily determine how and when water is used (a water shortage can modify the community knowledge models). Changes in water availability and quality cause families to respond seasonally. Changes in the community (the current Choyero community has resided in the area for centuries), technology (wells and pumps affecting groundwater extraction rates have been installed over the course of years and decades), and regulations (implemented on the annual to decadal scales) reflect how use rates of water change through time.

We further explore the utility of the graphical resilience framework by interpreting Table 5 and Fig. 7 with policy and management strategies in mind. We speculate on how the framework might be useful but have not tried to use it with Choyeros for goal-setting activities due to limitations associated with the COVID-19 pandemic. We recognize that when using this tool beyond this manuscript, any community's own perceptions, self-determined needs, and boundaries of interest should be prioritized when using or applying this framework.

We show that there is some overlap and, importantly, connectivity in the Choyero and groundwater systems, suggesting that there is a high potential for coupled human-natural resilience. The Choyero community shares water and builds social ties in ways that overlap in space and time. These responses encompass cultural norms and dynamic social networks. Their responses to limited water resources connect their social response scales to the scales of the associated water system changes.

People can be seen as dynamic agents of change for coupled system resilience (Newman and Dale 2005). So, when we observe gaps in the temporal and spatial response scales in the hydrological system (space between W1 and W2), we also see that the Choyeros management strategies bridge those gaps. Choyero active management strategies can change the structure of their boxes; this is considered transformative resilience (Barnes et al. 2020). By sharing water among neighbors, the community buffers against limits associated with short-term time and space changes in the water system such as the pumping from connected aquifers (e.g., P2 overlaps with W2). Responses such as water storage buffer the community from larger-scale changes in the water system (e.g., P3 overlaps with W1). Collectively, the networks and behaviors of the Choyero community connect the scales of the changing water systems.

Another way to use this framework is to identify areas without human- and hydrological-system overlap and understand these as "vulnerabilities" in the system. These vulnerabilities can then spark discussion and serve as starting points for policy and management strategy development. For example, first consider the box boundaries to generally represent critical thresholds relevant to the Choyero community at the time of study. If external processes come into play in the relevant system (e.g., if groundwater pumping increases dramatically) then the Choyero community may need to expand their geographic network for water sharing, expanding the $\mathrm{x}$-axis or scale of geographic connections. Development of strategies via informal social processes or formal policy can then create new boxes to be plotted within the graphical framework.

One Western/engineering approach would be to insert deep wells and disassociate the community from the springs. While there might be some benefits of more water security, the impacts on social organization could dramatically alter their current way of life. If we define a critical threshold as "assume Choyeros desire to be able to sustain their subsistence and not be forced to leave the ecology and their homes" then this approach may not be acceptable.

Within our graphical framework, we exclusively (and purposefully) focus our attention on that of the Choyeros, rather than including all possible stakeholder groups that could impact system resilience, such as ejido boards that own land in the region but reside in distant urbans areas, recent "amenity land buyers" who have purchased land in the region for strictly vacationing purposes on short timescales, NGOs with a footprint in the region but who are located in urban areas (e.g. Niparaja), and federal organizations that control water permitting (i.e. CONAGUA) and land conservation (i.e. CONABIO). The rationale for this analytic strategy is two-fold. First, our goal is to understand how the primary stakeholders interact with this system and what it portends for natural and cultural system resilience. This requires us to focus on Choyeros. This is the only social group that interacts with this system on a daily basis, while all other stakeholders reside outside the study site and only directly interact with its groundwater on a limited-scale and temporary basis. Second, all data-driven research involves trade-offs between resolution and extentthe higher the data resolution, the lower its extent, and vice versa. By exclusively focusing our attention on Choyeros, we 
gain considerable insight into the internal dynamics of this social system. While this analytic philosophy causes us to "black box" external social constraints and potential sources of conflict, it does allow us to better interpret results within this particular social system, and more importantly, allows us to discuss each data point with relevant stakeholders themselves. Last, while our analytic strategy focuses on the relationship between Choyeros and Giganta groundwater, there is no a prior reason it could not be scaled-up socially to include other more distally linked stakeholders.

As with any project with direct applications to communities and ecosystems, we must consider positionality and ethics. While members of the Choyero community expressed interest in applying this framework as a policy workshop, continued in-person sessions have been halted by the COVID-19 pandemic. We recognize that this case study is not applied directly with the Choyero community, as we hope that this framework someday will. We also acknowledge our position as Western-trained academics, and that demonstrating this framework should not dictate any policy decisions related to Choyero water management practices. With that context, we do believe that introducing this framework to the scholarly and practitioner community is a valuable tool for starting inter- and trans-disciplinary conversations about sustainability and resilience policy.

\section{Discussion of framework}

Frameworks are needed to assess the sustainability and resilience of coupled natural-human, socio-ecological, sociohydrologic systems that are scalable and transferrable (Cox et al. 2016; Garcia et al. 2016). This framework must also be used while considering its purpose, stakeholder goals, and limitations.

\section{Scalability}

We recognize that the spatial scale of this study is relatively small. This is not a large or urban system, and thus lacks socalled "big data" to map out socio-economic stratification and other differences. While we consider the dynamics of this Choyero community through the lens of their social support networks, future researchers working on larger scales or in more urban systems may need to work with representative stakeholders to consider the implications of capitalism, competition, and potential contradicting goals between groups. To this point, understanding small societies with attention to detail and holistic interactions is important for serving their needs and more thoughtfully engaging with planning and decisions that have complex impacts on real peoples' ways of living.

\section{Transferability}

In part due to its origins as an Earth science tool, we see that the framework can be used for many different earth processes such as landslides or flooding, and also other more human-centered systems such as recycling or mineral extraction.

This resilience framework is broadly useful because it can apply to other coupled human-natural systems, as well as help to evaluate multiple types of systems, such as ecologi$\mathrm{cal}$, and economic systems in addition to the ones presented here. The visual simplicity and clarity (as opposed to complex numerical models) can also be useful for quickly working with stakeholders and policy makers while maintaining the visual cues as reminders of uncertainty.

The simplicity and graphical interface of this resilience framework can be useful beyond water-related disciplinary boundaries and should be used in culturally grounded and equity-centered scenario planning (Sterling et al. 2017). This same spatial and temporal framework can be used to evaluate disconnects and overlap between adaptive and absorptive responses to change in coupled human-resource systems. For example, this framework could potentially be used to evaluate human systems related to energy, critical minerals, agriculture, and waste management to the biophysical response times of the earth systems that govern these resources. We encourage users to consider the important aspects of environmental justice, equity, and social recognition when using this framework to address stakeholder's concerns.

This tool demonstrates a collaborative, interdisciplinary workflow that sustainability scientists associated with a wide range of disciplines might use to more usefully engage in the planning process, which scientific perspectives have not consistently engaged with in the past (Freeth and Caniglia 2020).

\section{Limitations}

This graphical resilience framework is a tool strongly dependent on user goals or "acceptable scenario" building. We recognize that simply seeing overlap of system processes easily lead to non-resilient outcomes, such as overpumping of an aquifer removing water resources from a large community. However, it is important to use this tool in terms of desired goals and acceptable resilient or sustainable scenarios for water users, and other stakeholders like the dependent biodiversity and ecology.

This framework, or tool, helps users to know and define their goals, critically thinking about how the system works in the complex biophysical world. We emphasize that it is not 
a deterministic resilience "equation"; we discuss potential resilience as seen through understanding the complex, interrelated human and natural systems. Thus, it helps us communicate across disciplinary boundaries and social sectors to further explore and organize things beyond individual scales and help imagine futures that are comprehensively desirable.

Additionally, the framework can be of use before, during, and/or after a system disturbance, although we recommend using it in the preparation phase of resilience, planning for potential resilience before a disastrous system perturbation. We presented an example scenario of a system perturbation as understanding the system thoroughly across disciplines helps to develop a plan. This use of scenarios spurs innovation and allows planners, policy makers, and community members to envision different futures, and develop ways to prepare, mitigate, respond and recover from disturbances (Iwaniec et al. 2020).

In sum, we developed this framework as a result of interdisciplinary sustainability studies and recognize that it may not be the most useful tool for all sustainability or resilience studies, depending on the goals, needs, scales, and complexity of the system of interest.

\section{Conclusions}

We examine coupled human-natural systems to develop and demonstrate the efficacy of a graphical resilience framework. This framework expands on existing frameworks commonly used within the Earth sciences by overlaying social science information and themes, and introducing a narrative to explicitly compare disciplinary data within the context of resilience and sustainability planning. This framework provides a simple, useful, and transferable model for studying coupled human-natural systems. The framework, regarding policy and governance strategies, must prioritize the selfdetermination of the resource users and stakeholders at the spatio-temporal scales of interest.

A rural community, Choyeros, live in the Sierra de la Giganta and use springs and shallow hand-excavated wells to sustain their ranching and subsistence livelihoods. This coupled human-natural system presents an opportunity to explore spatial and temporal scales of resilience, or response to changes, of both the groundwater and social systems. Geochemical analyses of groundwater and interviews with 31 households within the subdelegation of Santa Maria de Toris evaluated the spatial connectivity of both the hydrologic and human systems, as well as demonstrated the temporal responses to system change. The Choyero social and hydrological systems had areas of overlap in our proposed framework, indicating that the community likely can respond to stresses on decadal and generational scales, but may be more vulnerable to changes on shorter, annual scales.
Additionally, the mixed methods used in this study do not rely on longitudinal data availability nor spatially extensive and resource-intensive data collection and is thus a feasible way to conduct similar studies in other coupled humannatural systems.

Supplementary Information The online version contains supplementary material available at https://doi.org/10.1007/s11625-022-01101-6.

Acknowledgements We recognize our funders: National Geographic Research and Exploration Grant Award \#HJ-099R-17, National Science Foundation IBSS-L Award \# 1620416, Society, Water and Climate (from the Global Change and Sustainability Center), Funding Incentive Seed Grant (University of Utah), iNterdisciplinary EXchange for Utah Science (NEXUS), and the EARTH core facilities. Thank you to M. Howitz and A. Jayo for participating in and contributing to this interdisciplinary experiment. Gracias por M. Amador Amador y la comunidad de Choyeros. We recognize that this study was performed on the ancestral territories of the Guaycura peoples. Data in support of the spring chemistry and social network analyses are hosted under the https://doi.org/10.5281/zenodo.5828380. This study was performed under IRB\# 00083096. Given the personal information contained in and used for these interviews and subsequent analyses, it is not possible to fully anonymize the data, and under IRB guidelines we cannot upload interview data directly.

\section{References}

Anderson K, Clow B, Haworth-Brockman M (2013) Carriers of water: aboriginal women's experiences, relationships, and reflections. J Clean Prod 60:11-17

Barnes ML, Wang P, Cinner JE, Graham NA, Guerrero AM, Jasny L, Lau J, Sutcliffe SR, Zamborain-Mason J (2020) Social determinants of adaptive and transformative responses to climate change. Nat Clim Change 10:1-6

Barr S, Devine-Wright P (2012) Resilient communities: sustainabilities in transition. Local Environ 17(5):525-532

Barron JA, Metcalfe SE, Addison JA (2012) Response of the North American monsoon to regional changes in ocean surface temperature. Paleoceanography 27:PA3206. https://doi.org/10.1029/ 2011PA002235

Bernard HR (2002) Interviewing: unstructured and semistructured research methods in anthropology: qualitative and quantitative methods. Walnut Creek. pp 203-212

Biggs R, Peterson GD, Rocha JC (2018) The Regime Shifts Database: a framework for analyzing regime shifts in social-ecological systems. Ecol Soc. https://doi.org/10.5751/ES-10264-230309

Bodin Ö, Crona B, Ernstson H (2006) Social networks in natural resource management: what is there to learn from a structural perspective? Ecol Soc. https://doi.org/10.5751/ES-01808-1102r02

Boelens R, Hoogesteger J, Swyngedouw E, Vos J, Wester P (2016) Hydrosocial territories: a political ecology perspective. Water Int 41(1):1-14. https://doi.org/10.1080/02508060.2016.1134898

Borgerhoff-Mulder M, Coppolillo P (2005) Conservation: linking ecology, economics, and culture. Princeton University Press, Princeton

Cariño M (2001) La oasisidad, núcelo de la cultura sudcaliforniana. Gaceta Ecológica 60:57-69. https://www.redalyc.org/pdf/539/ 53906005.pdf

Cartier KMS (2020) Keeping indigenous science knowledge out of a colonial mold. Eos. https://doi.org/10.1029/2019EO137505 
Caughman L, Plemmons N, Beaudoin F, Crim M, Shandas V (2020) The Scenario Collaboratory: a framework for integrating environmental assessments and scenarios into municipal planning. In: Environmental assessments. Edward Elgar Publishing

Comisión Nacional de Áreas Naturales Protegidas (2014) Estudio Previo Justificativo para el establecimiento del area natural protegida de competencia de la Federación con la category de Reserva de la Biosfera "Sierras La Giganta y Guadalupe", en el estado de Baja California. SEMARNAT: La Paz, BCS, Mexico

Cook PG (2003) A guide to regional groundwater flow in fractured rock aquifers. Seaview Press, Henley Beach, p 151

Cote M, Nightingale AJ (2012) Resilience thinking meets social theory: situating social change in socio-ecological systems (SES) research. Prog Hum Geogr 36(4):475-489

Cox M, Villamayor-Tomas S, Epstein G, Evans L, Ban NC, Fleischman F, Nenadovic M, Garcia-Lopez G (2016) Synthesizing theories of natural resource management and governance. Glob Environ Change 39:45-56

Cristiano E, ten Veldhuis MC, Van De Giesen N (2017) Spatial and temporal variability of rainfall and their effects on hydrological response in urban areas-a review. Hydrol Earth Syst Sci 21(7):3859-3878. https://doi.org/10.5194/hess-21-3859-2017

Crosby H (1981) Last of the Californios. Copley Books, La Jolla

Crosby HW (1994) Antigua California: mission and colony on the peninsular frontier. UNM Press, Albuquerque, pp 1697-1768

Darden L, Maull N (1977) Interfield theories. Philos Sci 44(1):43-64

de Grenade R, Nabhan GP (2013a) Agrobiodiversity in an oasis archipelago. J Ethnobiol 33(2):203-236

de Grenade R, Nabhan GP (2013b) Baja California peninsula oases: an agro-biodiversity of isolation and integration. Appl Geogr 41:24-35

de Grenade R, Nabhan GP, Olvera MC (2016) Oases of the Baja California peninsula as sacred spaces of agrobiodiversity persistence. Agric Hum Values 33(2):455-474

Díaz S, Demissew S, Carabias J, Joly C, Lonsdale M, Ash N, Larigauderie A, Adhikari JR, Arico S, Báldi A, Bartuska A (2015) The IPBES Conceptual Framework-connecting nature and people. Curr Opin Environ Sustain 14:1-16

Doorn N, Gardoni P, Murphy C (2019) A multidisciplinary definition and evaluation of resilience: the role of social justice in defining resilience. Sustain Resilient Infrastruct 4(3):112-123

Folke C, Carpenter SR, Walker B, Scheffer M, Chapin T, Rockström J (2010) Resilience thinking: integrating resilience, adaptability and transformability. Ecol Soc. https://doi.org/10.5751/ ES-03610-150420

Fontes JC, Garnier JM (1979) Determination of the initial 14C activity of the total dissolved carbon: a review of the existing models and a new approach. Water Resour Res 15(2):399-413

Freeth R, Caniglia G (2020) Learning to collaborate while collaborating: advancing interdisciplinary sustainability research. Sustain Sci 15(1):247-261

Garcia M, Portney K, Islam S (2016) A question driven socio-hydrological modeling process. Hydrol Earth Syst Sci 20(1):73-92

Habiba U, Kogachi A, Huy N, Shaw R (2012) Understanding adaptation practices in arid land ecosystem. In: Ecosystem-based adaptation. Emerald Group Publishing Limited

Han LF, Plummer LN (2016) A review of single-sample-based models and other approaches for radiocarbon dating of dissolved inorganic carbon in groundwater. Earth Sci Rev 152:119-142

Hedstrom P, Grund T (2020) An introduction to social network analysis and agent-based modeling using stata. Stata Press, College Station

Henrickson CN (2013) The Archaeology of Cueva Santa Rita: A Late Holocene Rockshelter in the Sierra de la Giganta of Baja California Sur, Mexico. University of California, Berkeley
Iwaniec DM, Cook EM, Davidson MJ, Berbés-Blázquez M, Georgescu M, Krayenhoff ES et al (2020) The co-production of sustainable future scenarios. Landsc Urban Plan 197:103744

Janvry AD, Gordillo G, Sadoulet E (1997) Mexico's second agrarian reform: household and community responses, pp 1990-1994

Kavanaugh MT, Oliver MJ, Chavez FP, Letelier RM, Muller-Karger FE, Doney SC (2016) Seascapes as a new vernacular for pelagic ocean monitoring, management and conservation. ICES J Mari Sci 73(7):1839-1850. https://doi.org/10.1093/icesjms/fsw086

Lade SJ, Walker BH, Haider LJ (2020) Resilience as pathway diversity: linking systems, individual, and temporal perspectives on resilience. Ecol Soc 25(3):19. https://doi.org/10.5751/ ES-11760-250319

Lampitt RS, Favali P, Barnes CR, Church MJ, Cronin MF, Hill KL, Kaneda Y, Karl DM, Knap AH, McPhaden MJ, Nittis KA (2010) In situ sustained Eulerian observatories. Proceedings of OceanObs' 09: Sustained Ocean Observations and Information for Society 1, pp 395-404

Lansing JS (2006) Perfect order: recognizing complexity in Bali. Princeton University Press, Princeton

Lerback JC, Bowen BB, Humphrey CE, Fernandez DP, Bernau JA, Macfarlan SJ, Schniter E, Garcia JJ (2022) Geochemistry and provenance of springs in a Baja California Sur mountain catchment. Groundwater. https://doi.org/10.1111/gwat.13177

Macfarlan SJ, Schacht R, Foley C, Cahoon S, Osusky G, Vernon KB, Tayler E, Henrickson C, Schniter E (2020a) Marriage dynamics in old Lower California: ecological constraints and reproductive value in an arid peninsular frontier. Biodemography Soc Biol 65(2):156-171. https://doi.org/10.1080/19485565.2020.1728685

Macfarlan SJ, Schacht R, Schniter E, Garcia JJ, Guevara Beltran D, Lerback J (2020b) The role of dispersal and school attendance on reproductive dynamics in small, dispersed populations: Choyeros of Baja California Sur, Mexico. PLoS ONE 15(10):e0239523

Macfarlan SJ, Schacht R, Bourland I, Kapp S, Glad T, Lewis L, Claflin S, Darmiento N, Clegg T, Thorpe C, Peppelar T, Nguyen B, Hall RG, Davis CS, Santiago M, Henrickson C (2021) NDVI predicts birth seasonality in historical Baja California Sur, Mexico: Adaptive responses to arid ecosystems and the North American Monsoon. Biodemography Soc Biol. https://doi.org/10.1080/19485 565.2020.1870924

Madani K, Shafiee-Jood M (2020) Socio-hydrology: a new understanding to unite or a new science to divide? Water 12(7):1941

Mao F, Clark J, Karpouzoglou T, Dewulf A, Buytaert W, Hannah D (2017) HESS Opinions: a conceptual framework for assessing socio-hydrological resilience under change. Hydrol Earth Syst Sci. https://doi.org/10.5194/hess-21-3655-2017

Massuel S, Riaux J, Molle F, Kuper M, Ogilvie A, Collard AL, Leduc C, Barreteau O (2018) Inspiring a broader socio-hydrological negotiation approach with interdisciplinary field-based experience. Water Resour Res 54(4):2510-2522

McLean H, Hausback BP, Knapp JH (1986) The Geology of WestCentral Baja Californa Sur, Mexico. U.S. Geological Survey Bulletin vol 1579, no. QE203.B34. https://pubs.usgs.gov/bul/1579/ report.pdf.

Meerow S, Pajouhesh P, Miller TR (2019) Social equity in urban resilience planning. Local Environ 24(9):793-808

Montanari A, Young G, Savenije HHG, Hughes D, Wagener T, Ren LL, Koutsoyiannis D, Cudennec C, Toth E, Grimaldi S, Blöschl G (2013) "Panta Rhei-everything flows": change in hydrology and society - the IAHS scientific decade 2013-2022. Hydrol Sci J 58(6): 1256-1275

Moore JE, Mascarenhas A, Bain J, Straus SE (2017) Developing a comprehensive definition of sustainability. Implement Sci 12(1):110

Nabhan GP, Garcia J, Routson R, Routson K, Carintilde M (2010) Desert oases as genetic refugia of heritage crops: persistence of 
forgotten fruits in the mission orchards of Baja California, Mexico. Int J Biodivers Conserv 2(4):56-69

Newman L, Dale A (2005) Network structure, diversity, and proactive resilience building: a response to Tompkins and Adger. Ecol Soc. https://doi.org/10.5751/ES-01396-1001r02

Ofterdinger U, MacDonald AM, Comte JC, Young ME (2019) Groundwater in fractured bedrock environments: managing catchment and subsurface resources-an introduction. Geol Soc Lond Spec Publ 479(1):1-9

Ostrom E (2009) A general framework for analyzing sustainability of social-ecological systems. Science 325(5939):419-422

Pascual U, Balvanera P, Díaz S, Pataki G, Roth E, Stenseke M, Watson RT, Dessane EB, Islar M, Kelemen E, Maris V (2017) Valuing nature's contributions to people: the IPBES approach. Curr Opin Environ Sustain 26:7-16

Rockström J, Falkenmark M, Folke C, Lannerstad M, Barron J, Enfors E, Gordon L, Heinke J, Hoff H, Pahl-Wostl C (2014) Water resilience for human prosperity. Cambridge University Press, Cambridge

Resilience Alliance (2010) Assessing resilience in social-ecological systems: workbook for practitioners. http://www.resalliance.org/ 3871.php Accessed Mar 2021

Ruhl HA, André M, Beranzoli L, Çăgatay MN, Colaço A, Cannat M, Dañobeitia JJ, Favali P, Géli L, Gillooly M, Greinert J (2011) Societal need for improved understanding of climate change, anthropogenic impacts, and geo-hazard warning drive development of ocean observatories in European Seas. Prog Oceanogr 91(1):1-33. https://doi.org/10.1016/j.pocean.2011.05.001

Salinas Zavala CA, Leyva Contreras A, Lluch Belda D, Diaz Rivera E (1990) Distribución geográfica y variabilidad climática de los regimens pluciomeétricos en Baja California Sur, México. Atmosfera 3:217-237

Schacht R, Macfarlan SJ, Meeks H, Cervantes PL, Morales F (2020) Male survival advantage on the Baja California peninsula. Biol Lett. https://doi.org/10.1098/rsbl.2020.0660

Scheffer M, Carpenter S, Foley JA, Folke C, Walker B (2001) Catastrophic shifts in ecosystems. Nature 413(6856):591-596

Schniter E, Macfarlan SJ, Garcia JJ (2020) Choyero ethnobiological knowledge survey. Mendeley Data 1. https://doi.org/10.17632/ hgd8zdyf2c. 1

Schniter E, Macfarlan SJ, Garcia JJ, Ruiz-Campos G, Beltran DG, Bowen BB, Lerback JC (2021) Age appropriate wisdom? Ethnobiological knowledge ontogeny in Pastoralist Mexico. Hum Nat. https://doi.org/10.1007/s12110-021-09387-8

Secretaría de Desarrollo Social (2019) Catálogo de Localidades. Accessed 30 Aug 2019. http://www.microrregiones.gob.mx/catloc/LocdeMun.aspx?tipo $=$ clave $\&$ campo $=$ loc\&ent $=03 \&$ mun $=003$

Shaw S, Francis A (2014) Deep blue: critical reflections on nature, religion and water. Routledge, Milton Park
Sivapalan M, Savenije HH, Blöschl G (2012) Socio-hydrology: a new science of people and water. Hydrol Process 26(8):1270-1276

Sterling E, Ticktin T, Morgan TKK, Cullman G, Alvira D, Andrade P, Bergamini N, Betley E, Burrows K, Caillon S, Claudet J (2017) Culturally grounded indicators of resilience in social-ecological systems. Environ Soc 8(1):63-95

Sterling E, Pascua P, Sigouin A, Gazit N, Mandle L, Betley E, Aini J, Albert S, Caillon S, Caselle J, Cheng S (2020) Navigating multidimensional measures of sustainability and well-being across scales. Sustain Sci 15(4):1129-1147

Thompson KL, Lantz T, Ban N (2020) A review of Indigenous knowledge and participation in environmental monitoring. Ecol Soc. https://doi.org/10.5751/ES-11503-250210

Trosper RL (2005) Emergence unites ecology and society. Ecol Soc. https://doi.org/10.5751/ES-01239-100114

Vernon EW (2002) Las Misiones Antiguas: The Spanish Missions of Baja California. Viejo Press, Santa Barbara

Walker B, Holling CS, Carpenter SR, Kinzig A (2004) Resilience, adaptability and transformability in social-ecological systems. Ecol Soc 9(2)

Walker BH, Abel N, Anderies JM, Ryan P (2009a) Resilience, adaptability, and transformability in the Goulburn-Broken Catchment, Australia. Ecol Soc 14(1):12. https://doi.org/10.5751/ ES-02824-140112

Walker BH, Abel N, Anderies JM, Ryan P (2009b) Resilience, adaptability, and transformability in the Goulburn-Broken Catchment, Australia. Ecol Soc 14(1):12. http://www.ecologyandsociety.org/ vol14/iss 1/art12/.

Wasserman S, Faust K (2009) Social Network Analysis. 19. Aufl

Weingart P (2010) A short history of knowledge formations. The Oxford handbook of interdisciplinarity, pp 3-14

Western D (1982) The environment and ecology of pastoralists in arid savannas. Dev Change 13(2):183-211

Wilson NJ (2018) More precious than gold: Indigenous water governance in the context of Modern land claims in Yukon. Doctoral Dissertation. University of British Columbia

Wutich A, Budds J, Jepson W, Harris LM, Adams E, Brewis A, Cronk L, DeMyers C, Maes K, Marley T, Miller J (2018) Household water sharing: a review of water gifts, exchanges, and transfers across cultures. Wiley Interdiscip Rev Water 5(6):e1309

Xu L, Gober P, Wheater HS, Kajikawa Y (2018) Reframing sociohydrological research to include a social science perspective. J Hydrol 563:76-83

Publisher's Note Springer Nature remains neutral with regard to jurisdictional claims in published maps and institutional affiliations. 